Original Contribution

\title{
FIELD EVALUTION OF CONTROLING METHODS OF MANGO FRUIT FLIES BACTROCERA ZONATA (DIPTERA: TEPHRITIDAE) IN THE SOUTHERN PART OF IRAN
}

\author{
M. Khosravi ${ }^{1,2}$, N. Sahebzadeh ${ }^{2}$, R. Kolyaie ${ }^{3}$, A. Mokhtari ${ }^{2}$ \\ ${ }^{1}$ Department of Plant Protection, Agriculture and Natural Resource Research Center of Baluchestan, Iran \\ ${ }^{2}$ Department of Plant Protection, Faculty of Agriculture, University of Zabol, Zabol, Iran \\ ${ }^{3}$ Department of Agricultural Entomology, Iranian Research Institute of Plant Protection, Tehran, Iran
}

\begin{abstract}
Purpose: Bactrocera zonata (Diptera, Tephritidae), is considered as a dangerous pest of mango in the south of Iran, which its control is one of the main concerns of farmers who are facing numerous problems. To assay the different methods for controlling $B$. zonata, this study was carried out.

Method: The treatments were, A) spraying 7\% methyl eugenol+7\% technical malathion on trunk and tree branches, B) soaking 8-10 layers of jute sacks with previous treatment that were attached to tree branches, C) bucket trap along with chipboard that was saturated with $6 \mathrm{ml}$ of methyl eugenol, D) spraying $3 \%$ protein hydrolysate $+3 \mathrm{ppm}$ malathion (EC 57\%) on the trunk and tree branches, E) spraying 3\% sugar permit+3 ppm malathion on the trunk and tree branches, and F) control (no treatment). The experiments were repeated at two consecutive years.

Results: The results confirmed that the differences among treatments and the effect of the year on the treatments were significant $(p>1 \%)$. The treatment D captured the highest numbers of fruit flies in both years of replications. The treatments had significant effect on percentage of fruit infestation.

Conclusion: The findings confirmed that treatments $\mathrm{C}$ and $\mathrm{B}$ had the greatest impact on pest control.
\end{abstract}

Key words: mango Fruit Fly, malathion, methyl Eugenol, protein Hydrolysate, trapping system, IPM

\section{INTRODUCTION}

Because of hot and humid climates in summer and mild in winter, Chabahar (Sistan and Baluchestan, Iran) can develop many tropical and subtropical plants include bananas, mango, papaya, ziziphus, chico, tamarind, coconut, guava, dates and citrus, etc. Unfortunately, the absence of unified gardens for suitable commercial cultivars is a major cause of underdevelopment of mango orchards in this province. Important pests of mango including Erosomyia mangiferae (Diptera, Cecidomyiidae), Procontarinia mattiana (Dipitera, Cecidomyiidae), Psylla pyri (Hemiptera: Psyllidae), Apodiphus amygdali (Hemiptera, Pentatomidae) and Bactrocera zonata (Diptera, Tephritidae) cause economic damage coincide with the flowering and

*Correspondence to: Najmeh Sahebzadeh, Tel. +5431232155, Fax +5431232100, E mail-

najmeh.sahebzadeh@gmail.com appearance of their blossoms and before physiological ripening of mango fruits $(1,2)$.

The family Tephritidae (fruit flies) includes more than 5000 species worldwide, approximately 1400 species of which develop in fleshy fruits (3). Nearly 250 of these species feed on plants which could cause economic damage (4). Most of these flies are polyphagous, have high capability of reproduction, can quickly spread in a wide area and these have made them a serious threat to crops (5).

In recent decades, fruit flies are one of the most economically important groups of insects in the Baluchestan Region (Iran). They cause up to $90 \%$ of damage to fruits in the region. Economic damage of mango fruit flies on horticultural products are an alarm to all those who involved in plant protection issues, indication the importance of Tephritidae fruit flies damages in this area (6). 
Mango fruit fly, Bactrocera zonata (Saunders) is known as Dacus zonatus, Dasyneura zonata and Rivellia persicae Bigot (7). This fruit fly has been reported from various countries including Bangladesh, Egypt, Emirates, Indonesia, Iran, Laos, Mauritania, Myanmar, Nepal, Oman, Pakistan, Saudi Arabia, Sri Lanka, Thailand, United Arab, and Vietnam. Fruit fly has not been reported so far from the continents of Europe and the Pacific (8). Mango fruit fly has a wide host range and the main hosts are peach, mango, guava, citrus, fruit trees, vegetables and weeds (4). The female flies lay their eggs by sitting on ripening fruits and dipping eggs in the skin of fruits. Attacked fruits usually show signs of oviposition puncture $(9,10)$. After hatching, larvae penetrate into internal tissues of the fruit, leading to digging tunnels. The larvae of different ages can be seen usually in an infested fruit, indicating frequently laying and generation interference. First instars larval activity is limited only on the surface below the laid eggs, but the second and third larval instars often penetrate the fruit and result in complete deterioration of the fruit (cited in 11).

Trapping system is one of the most common tools for bio-systematic studies and bioecological control of fruit flies. This technique is used to determine the presence or absence of a pest in an area, track and identify distribution range, calendar time to control, effectiveness of control methods, hosts and host sequence, fluctuations in population density, spatial distribution, time of appearance and economic damages threshold and early detection of pest (12). The use of attractants is one of methods used in pest tracking and hunting program. Males of fruit flies like $B$. zonata attract to methyl eugenol which is a phenylpropanoid compound and is found naturally in many plant species (13). The protein hydrolysate as another attractant which is commonly used to trap fruit flies. It is well documented that $B$. zonata can be monitored by traps baited with the male lure methyl eugenol, which attracts male flies at very low concentrations and insecticide (14, 15). Protein hydrolysate combined with malathion as a bait spry were first used for control of $B$. dorsalis (16). A large eradication program with wooden blocks as bait stations has been very successful for controlling B. zonata populations during 2008 to 2009 in Egypt (17).

Ruresh et al. (18) examined the effect of different attractants on a number of male flies captured by parapheromone traps in guava orchards and stated that the efficiency of wicked cotton (cotton compressed and saturated with 6 $\mathrm{ml}$ of methyl eugenol) lasts up to 9 weeks.

Chiua (19) demonstrated that flattened fibers (chipboard) impregnated with methyl eugenol and Dichlorvos efficiently controlled the fruit flies. Marwat et al. (20) used cotton (one per hectare) as a methyl eugenol dispenser in the guava orchards that the rate of population decline was estimated at $77.27 \%$.

In another study, Verghese et al. (21) conducted a research to standardize a pre and post-harvest integrated management for $B$. dorsalis to obtain fruit fly-free and residue-free mango fruits. The results showed that a pre harvest IPM combination of male annihilation technique using methyl eugenol as a lure and sanitation brought down $B$. dorsalis infestation to $5.00 \%$ from an infestation ranging from $17-66 \%$ in control in both years of application.

Kafu et al. (22) reported that McPhil trap baited with methyl eugenol (49\%) and spinasad (2\%) captured the males of fruit flies. The results showed that this method as an effective technique for controlling the male insects could be used on a large scale to manage the multiple species of fruit flies.

Very little research has been done in Iran on proper methods to control mango fruit fly. Cheraghian (23) studied the various fruit flies and examined their control methods in Iran, and noted that attractants such as protein hydrolysate combined with malathion, ammonium acetate, attract-and-kill method, Tephri trap, Cera trap, McPhail trap, Jackson trap, and bait spray in various products are used to control this group of pests.

According to the behavior of mango fruit fly to attractants such as methyl eugenol and protein hydrolysate, so in this study we have assayed different methods of control using attractants and pesticide malathion to select the best method for pest control in the mango orchard under subtropical climate in Iran.

\section{MATERIALS AND METHODS}

\section{Chemicals}

Chemicals including methyl eugenol, protein hydrolysate, and malathion EC75\% were purchased from Golsam Gorgan company (Gorgan, Iran). Technical malathion was 
provided by Syngenta Crop Protection AG (Switzerland).

\section{Experimental design and treatments}

The present study was conducted during 20122014 as a randomized complete block design with five treatments and a control treatment. Each treatment consisted of six replicates in mango orchards in Tiskupan (Chabahar, Sistan
KHOSRAVI M., et al.

and Baluchestan, Iran). Each replication included a mango tree, and totally 36 mango trees were selected with identical horticultural conditions. The experimental treatments were:

A) Spraying $7 \%$ methyl eugenol with the technical malathion (7\%) on trunk and main branches of the tree (Figure 1)

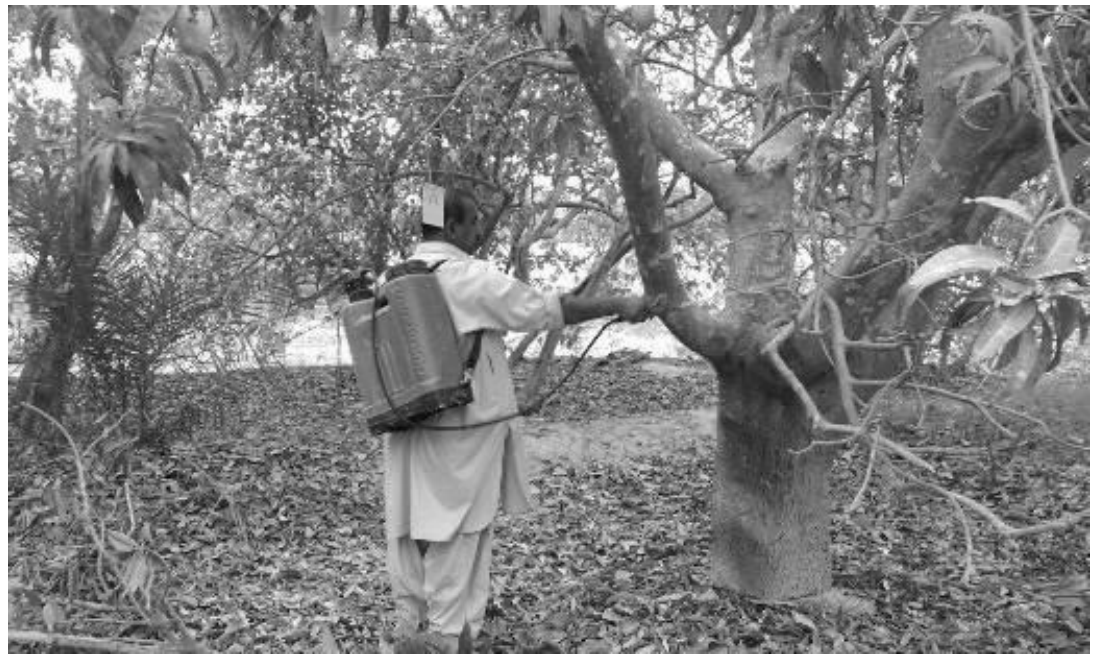

Figure 1. Spraying treatment A (7\% methyl eugenol+the technical malathion (7\%)+86\% water) on a mango tree

B) Soaking 8-10 layers of jute sacks with $7 \%$ methyl eugenol and $7 \%$ technical malathion. Final volume of treatment was adjusted by adding $86 \%$ water.
Then jute sacks were hanged on tree branches at a height of 1.5 meters above ground after removing extra solution (Figure 2).

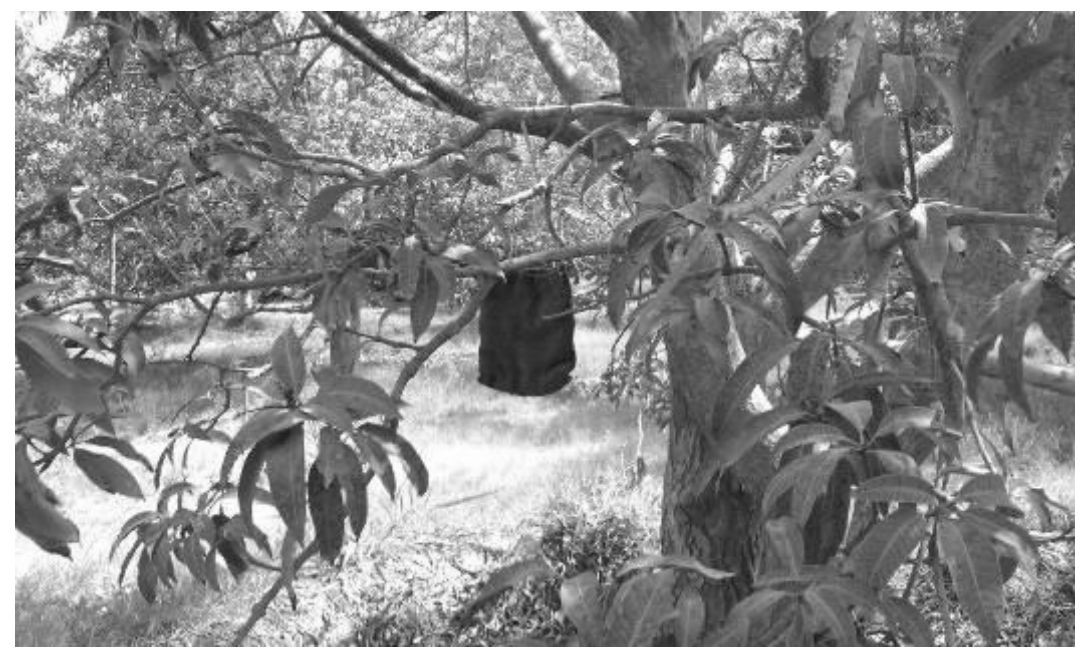

Figure 2. Hanging the soaked jute sacks with treatment B (7\% methyl eugenol+the technical malathion $(7 \%)+86 \%$ water) on a branch of mango tree

C) A piece of chipboard $\left(6 \times 3 \times 2 \mathrm{~cm}^{3}\right)$ was saturated with methyl eugenol $(6 \mathrm{ml})$ and were installed by wires into the bucket trap solution inside the bucket (2 liters of water (Figure 3) while did not contact with and $2 \mathrm{ml}$ dishwashing liquids), 
D) Spraying $3 \%$ protein hydrolysate and malathion (EC 57\%) in concentration of 3 ppm on the trunk and branches of trees,

E) Spraying 3\% sugar permit with malathion (EC 57\%) at a ratio of $3 \mathrm{ppm}$ on the trunk and branches of trees, and
KHOSRAVI M., et al.

F) Control (no treatment was carried out on the tree) 6) control (no treatment).

All concentrations and volumes of chemicals were determined by preliminary experiments.

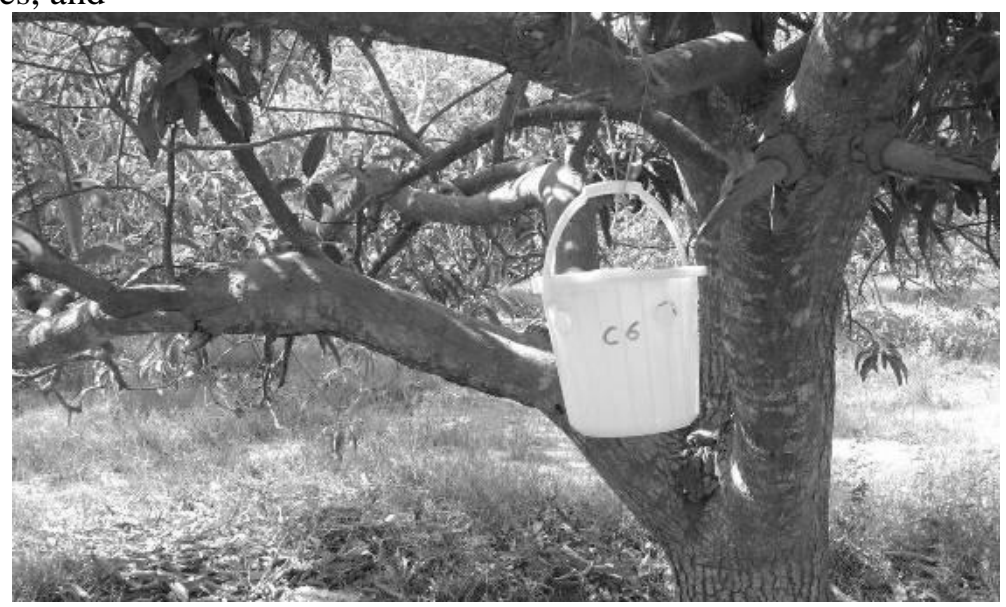

Figure 3. Hanging the bucket trap (treatment C) on a branch of mango tree

\section{Insect sampling after treatment}

Treatments were applied in March before the start of the mango fruit fly activity, and when mango fruits were green and immature. Replacement or renewal intervals of treatments were as follows until harvest:

(a) Each seven to ten day for treatments of A, B, $\mathrm{D}$, and $\mathrm{E}$ depending on the ambient temperature, and (b) Every month for treatment C.

Hunting rate of fruit flies in all treatments was counted at regular intervals to evaluate the effectiveness of each method. Checking and counting of flies inside the trap were enough for treatment $\mathrm{C}$; but thick plastic covers were spread at the foot of the tree at the size of crown in the other treatments (Figure 4). The covers were fastened firmly on one side with a rope to a tree, and their margins were fixed by putting stones on them. In this experiment, the fruit flies were collected daily on the plastic covers, transported to the laboratory, and then counted. In addition, 12 mango fruits were sampled from any tree from four directions and three different heights to determine the infestation percentage of fruits in each treatment. So, 432 fruits were analyzed for 36 trees. The fruits that female insects laid eggs in them turned yellow in oviposition sites and had a softening mode. Meanwhile, larval activity was characterized by creating gap in infested fruits and thus infestation of flies was determined for each treatment.

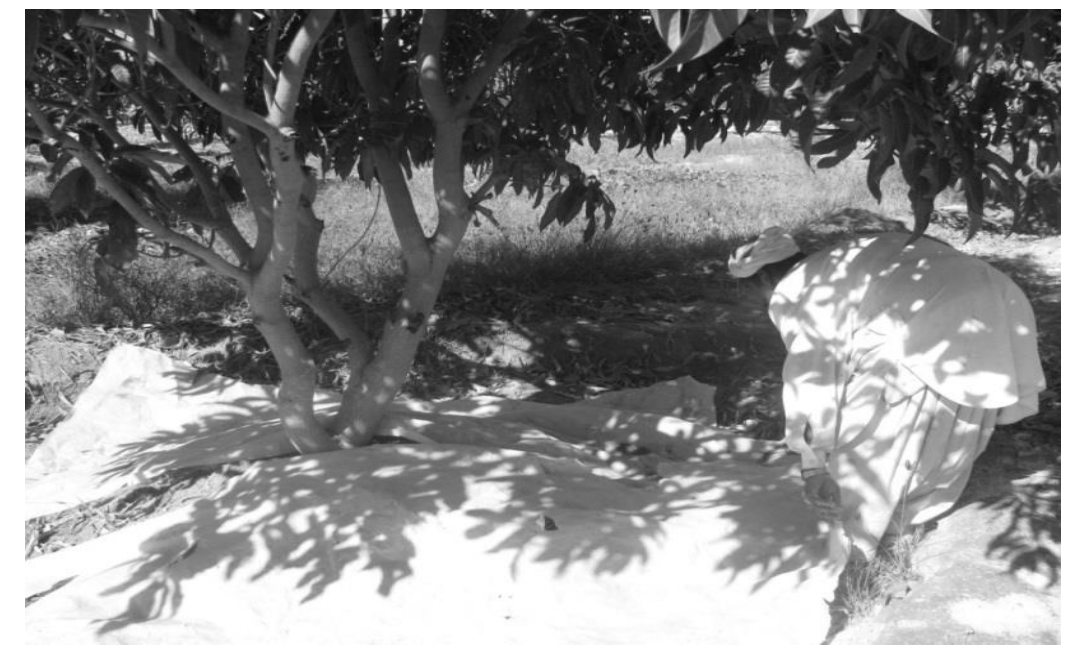

Figure 4. Spreading thick plastic covers under the tree crown after treatments (A, B, D, and E) 


\section{Data analysis}

Data were analyzed using SAS statistical software (24). Least Significant Difference (LSD) test was used to separate means of parameters significant at $95 \%$ confidence level. To assay the effectiveness of the use of attractants, the numbers of infested fruits were converted to percent for uniformity of data obtained from the effects of treatments, and the statistical analysis was then performed on them.

\section{RESULTS}

With regard to regular sampling and counting mango fruit flies trapped in the two years of the
KHOSRAVI M., et al. project, it became clear that the pest population significantly was lower in the second year of implementation than the first year (Table 1). Treatment D (protein hydrolysate and malathion on tree trunks) with the means of 786 and 493 flies showed the highest number of capturing; and treatment $\mathrm{E}$ (a mixture of sugar permit and malathion on tree trunks) with the means of 183 and 58 flies indicated the minimum flies captured (Table 1).

Table 1. Mean numbers of the captured fruit flies by the experimental treatments during 2012-2014

\begin{tabular}{cllc}
\hline \multirow{2}{*}{ Treatment } & & \multicolumn{2}{c}{$\begin{array}{c}\text { Mean numbers of captured } \\
\text { fruit flies by each treatment }\end{array}$} \\
\hline & & $1^{\text {st }}$ year & $2^{\text {nd }}$ year \\
\cline { 3 - 4 } A & Methyl eugenol and malathion on tree trunks & 227 & 403 \\
B & $\begin{array}{l}\text { The soaked jute sacks with treatment methyl eugenol+ the } \\
\text { technical malathion on a branch of mango tree } \\
\text { Bucket trap with a piece of chipboard saturated with methyl } \\
\text { eugenol (6 ml)+water and dishwashing liquids }\end{array}$ & 630 & 407 \\
C & $\begin{array}{l}\text { protein hydrolysate and malathion on tree trunks } \\
\text { D }\end{array}$ & 786 & 352 \\
E & Sugar and malathion on tree trunks & 58 & 493
\end{tabular}

Based on the results of analysis of variance (ANOVA), the difference between treatments was significant at $1 \%$ level (Table 2).

Table 2. Analysis of variance of the infested fruits (\%) post treatments

\begin{tabular}{lllll}
\hline Source & $\begin{array}{l}\text { Degree of } \\
\text { freedom }\end{array}$ & Sum of squares & Mean of squares & F value \\
\hline Year & 1 & 4243.93 & 4243.93 & $107.76^{* *}$ \\
$\begin{array}{l}\text { Replication } \\
\text { Year } \times\end{array}$ & 5 & 103.41 & 68.20 & $0.53^{\text {ns }}$ \\
replication & 5 & 417.84 & 83.56 & $1.32^{\text {ns }}$ \\
Treatment & 5 & 24304.48 & 4860.89 & $123.43^{* *}$ \\
Year $\times$ treatment & 5 & 4879.32 & 975.86 & $0.78^{\text {ns }}$ \\
Error & 50 & 1969.09 & 39.38 & \\
Total & 71 & 35918.10 & & \\
\hline
\end{tabular}

${ }^{*} p<0.05,{ }^{* *} p<0.01, \mathrm{~ns}:$ not significant.

Means comparison also was performed for the percentage of infested fruits and it was found that different treatments had significant effect on the infestation percentage of the fruit (Table 3). 


\begin{tabular}{ll}
\hline Treatment & Percentage of the infested fruits by flies \\
\hline C & $5.67 \pm 1.63 \mathrm{~d}$ \\
B & $9.02 \pm 2.60 \mathrm{dc}$ \\
D & $11.22 \pm 3.24 \mathrm{c}$ \\
A & $13.88 \pm 4.01 \mathrm{c}$ \\
E & $30.55 \pm 8.82 \mathrm{~b}$ \\
control & $58.56 \pm 16.92 \mathrm{a}$ \\
\hline
\end{tabular}

A: Methyl eugenol and malathion on tree trunks, B: The soaked jute sacks with treatment methyl eugenol+ the technical malathion on a branch of mango tree, C: Bucket trap with a piece of chipboard saturated with methyl eugenol $(6 \mathrm{ml})+$ water and dishwashing liquids, D: protein hydrolysate and malathion on tree trunks, E: Sugar and malathion on tree trunks

The results showed that the treatment of bucket traps (treatment $\mathrm{C}$ ) had the greatest impact on pest control. By using this treatment, the mean infestation reached to the lowest level $(5.67 \%)$ and after that the treatment B was located in the same group. In this treatment, the mean infestation of the fruit was $9.02 \%$.The use of protein hydrolysate mixed by malathion on tree trunks and the use of methyl eugenol mixed by malathion on tree trunks respectively with the mean infestation of $11.12 \%$ and $13.88 \%$ were subjected to group c. The use of the mixture of permit sugar and malathion on the tree trunks with the mean infestation of $30.55 \%$ was in the group $\mathrm{b}$ and the control treatment as expected had the highest infestation percentage of $58.56 \%$ (Table 3).

\section{DISCUSSION}

The mango fruit flies cause considerable economic damage in the region of Baluchestan, Iran. In the current study, the sexual and nutritional attractants were used in different methods to decrease the damage resulting from the mango fruit flies in mango and other tropical products. Methyl eugenol is a powerful attractant to male insects in some Bactrocera spp. (22).

The combination of methyl eugenol and malathion attracted the male mango fruit flies and so mating would be disrupted, reducing pest populations to very low levels effectively. The use of low-risk insecticides such as malathion together with protein hydrolysate as poisoned bait by attracting both male and female insects toward protein source had the highest level of hunting among the treatments. The poisoned bait that is sprayed as spot on the trunk and main branches of mango trees had effective results than sprayed coating on the tree and bring less damage to natural enemies. Regardless of the type chemical attractants, the method used was important in the transition effects.

The effect of methyl eugenol dispensers to catch the male of Dacus zonatus was evaluted under field conditions. The results showed that methyl eugenol attracted the maximum numbers of these fruit fly males which could be potentially use for monitoring and control of this pest in the orchards (14).

A research with treatments containing methyl eugenol $(2 \mathrm{ml})$ and malathion (EC50) used nutritional attractants including protein hydrolysate, palm extract, sugar and ripe mango. The results showed that mango fruit fly populations were more attracted to the protein hydrolysate compared to other treatments (25). These results confirmed our findings.

Our results confirmed that of the capturing rate of fruit flies after treatments within two consecutive years was lower in the second year than the first year. This decline could be due to regular actions of treating in the first year. However, since mango had been cultivated at the desired location mixed with guava (local olives) and ziziphus that are the favorite hosts of the mango fruit flies, the remaining population of flies could continue to survive on these hosts and revive their populations in the second year. For this reason, we recommend planting mango mixed with other tropical fruits should be avoided to prevent damage the polyphagous fruit flies.

Results showed that bucket traps and jute sacks treatments reduced the level of damages respectively by $5.67 \%$ and $9.02 \%$. In these methods, methyl eugenol led to a reduction in losses by attracting male mango fruit flies and impairing mating. Based on the results, the highest rate of adult insect capture was related to the treatment of protein hydrolysate, which 
was recorded at 786 and 473 respectively in the first and second years of testimplementation. It seems that the simultaneous use of hydrolyzed protein in a bucket traps along with methyl eugenol and malathion destroyed significant part of the population of pests and disrupted in mating in order to significant reduction in damages.

\section{CONCLUSION}

The power of flight and wide spread of pest, it is recommended that pest control to be done harmoniously in an area where farmers can control any damages alone. On the other hand, with regard to the illegal importation of agricultural inputs from the Pakistan border and the possibility of importing various pests of the country, it is suggested to identify other fruit flies that are active on tropical and subtropical products in Baluchestan and coordinated control of these pests. In addition, biological factors controlling these pests such as natural enemies and the possibility of mass rearing of biological agents should be identified.

\section{REFERENCES}

1. Nadeem, M.K., Ahmed, S., Ashfaq, M., and Sahi, S.T., Evolution of resistance to different insecticides against field populations of Bactrocera zonata (Sunders) (Diptera: Tephritidae) in Multan, Pakistan. Pakistan Journal of Zoology, 44(2): 495501, 2012.

2. Sarwar, M., Hamed. M., Yousaf, M., and Hussain, M., Surveillance on population dynamics and fruits infestation of Tephritid fruit flies (Diptera: Tephritidae) in Mango (Mangifera indica L.) orchards of Faisalabad, Pakistan. International Journal of Scientific Research in Environmental Sciences. 2(4):113-119, 2014.

3. Aluja, M., and Norrbom, A., Fruit Flies (Tephritidae): Phylogeny and Evolution of Behavior. CRC Press, USA, 1999.

4. White, I.M., and Elson-Harris, M.M., Fruit Flies of Economic Significance. Their Identification and Bionomics. Wallingford, UK. CAB International, 1994.

5. Rizk, M.M.A., Abdel-Galil, F.A., Temerak, S.A.H., and Darwish, D.Y.A., Relative preference of peach fruit fly, Bactrocera zonata (Saunders) (Diptera: Tephritidae) to some fruit and vegetables under laboratory conditions. Archives of Phytopathology and Plant Protection, 47 (11): 1376-1380, 2014.

6. Khosravi, M., and Shafaghi, F. Studies on identification and population dynamics of fruit flies (Diptera: Tephritidae) on Mango and Guava in Baluchestan. Plant Pest Research, 3(3): 1-9, 2013.

7. White, I.M., and Evenhuis, N.L., New species and records of Indo-Australasian Dacini (Diptera: Tephritidae). Raffles Bulletin of Zoology, 47(2):487-540, 1999.

8. CABI/EPPO 2001. Bactrocera zonata. Distribution maps of pest, no.125 $\left(2^{\text {nd }}\right.$ revision) $\mathrm{CAB}$ International walling ford (GB).

9. Qureshi, Z., Hussain, T., Carey, J.R., and Dowell, R.V., Effects of temperature on development of Bactrocera zonata (Saunders) (Diptera: Tephritidae). PanPacific Entomologist, 69(1):71-76, 1993.

10.Shehata, N.F., Younes, M.W.F., and Mahmoud, Y.A., Biological studies on the peach fruit fly, Bactrocera zonata (Saunders) in Egypt. Journal of Applied Science and Research, 4: 1103-1106, 2008.

11.Halawa, S.M., El-Hosary R.A.A., Mosallam, A.M.Z., El-Khayat, E.F., and Ismail, M.M.S. Toxicological, biological and biochemical effects of certain insecticides on Bactrocera zonata (Saunders) (Diptera, Tephritidae). American-Eurasian Journal of Toxicological Sciences, 5 (3): 55-65, 2013.

12.Rizk, M.M.A., Abdel-Galil, F.A., Temerak, S.A.H., and Darwish, D.Y.A. Factors affecting the efficacy of trapping system to the peach fruit fly (PFF) males, Bactrocera zonata (Saunders) (Diptera: Tephritidae), Archives Of Phytopathology And Plant Protection, 47 (4): 490-498, 2014.

13.Tan, K.H., and Nishida, R. Methyl eugenol: Its occurrence, distribution, and role in nature, especially in relation to insect behavior and pollination. Journal of Insect Science, 12 (56): 1-76, 2012.

14.Qureshi, ZA, Siddiqui, Q.H., and Hussain, T., Field evaluation of various dispensers for methyl eugenol, an attractant of Dacus zonatus (Saund.) (Dipt., Tephritidae). Journal of Applied Entomology, 113(4): 365-367, 1992.

15.Khan, S., Hussain, S., Maula, F., Asif Khan, M., and Shinwari, I. Efficacy of different lures in male annihilation technique of peach fruit fly, Bactrocera zonata (Diptera: Tephritidae). Journal of Entomology and Zoology Studies, 3(4): 164-168, 2015.

16. Roessler, Y. Insecticidal bait and cover sprays. pp. 329-336. In: A.S. Robinson, and G. Hooper, (eds), Fruit Flies, Their Biology, Natural Enemies and Control. Elsevier, Amsterdam, The Netherlands, 1989. 
17.FAO/IAEA, Trapping Guidelines for areawide fruit fly programmes. Vienna, Austria: International Atomic Energy Agency, 2010.

18.Ruresh , Z., Bughio, A., and Hussain, T., Field evaluation of various dispenser for methyl Eugenol and attractant of Dacus zonata (Dip ., Tephritidae ). Journal of Applied Entomplogy, 113(4): 365-367, 1992.

19.Chua, T. H., An evaluation of ten methyl eugenol trap types for trapping Bactrocera Malaysian A and B (Dipt., Tephritidae) in Malaysia, Journal of Applied Entomology,116(5): 505-509, 1993.

20.Marwat, N. K., Hussian, N., and Khan, A. Suppression of population and infestation of Dacus spp. By male annihilation in guava orchard. Pakistan Journal of Zoology, 24(1): 82-84, 1992.

21.Verghese, A., Sreedevi, K., and Nagaraju, D. K. Pre and post-harvest IPM for the mango fruit fly, Bactrocera dorsalis
KHOSRAVI M., et al.

(Hendel). Fruit Flies of Economic Importance: From Basic to Applied Knowledge, Proceedings of the 7th International Symposium on Fruit Flies of Economic Importance. pp. 179-182, 2006.

22.Kafu, A. A., Hassan, N., Badi, A. A., and Zanati, A. Evaluation of the efficacy of zonatrac system (lure and kill) to control Peach fruit fly Bactrocera zonata by application of male annihilation technique. Tunisian Journal of Plant Protection, 7(2): 127, 2012.

23. Cheraghian, A. Introduction of fruit flies Ceratitis, Bactrocera, Dacus and Ragoletis from Iran. Tunisian Journal of Plant Protection. 7(2): 117, 2012.

24.SAS Institute. PROC user's manual, version 9.2. SAS Institute, Cary, NC, 2008 .

25.Agarwal, M.L., and Kumar, P. Effect of weather parameters on population of peach fruit fly, Bactrocera zonata (Saunders). Entomon, 24: 81-84, 1999. 